Article

\title{
New Experiment of Diesel Exhaust Treatment by Atmospheric Pressure Plasma-Wood Fiber Combination
}

\author{
Xiurong Guo ${ }^{1, *}$, Khanh Hop Ha ${ }^{1,2}$ and Danfeng Du ${ }^{3}$ \\ 1 Mechanical and Electrical Engineering Institute, Northeast Forestry University, Harbin 150040, China; \\ hakhanhhop1987@nefu.edu.cn \\ 2 Department of Science and Technology, Quang Ninh 200000, Vietnam \\ 3 Transportation College, Northeast Forestry University, Harbin 150040, China; dudfeng@nefu.edu.cn \\ * Correspondence: guoxrong@nefu.edu.cn
}

Received: 29 March 2020; Accepted: 19 May 2020; Published: 21 May 2020

\begin{abstract}
Herein, a novel process of diesel exhaust purification by non-thermal plasma combined with wood fiber has been investigated to understand the effect of purification efficiency on the emission. The dielectric barrier discharge (DBD) and wood fiber (WF) improved removal efficiency of nitrogen oxide $\left(\mathrm{NO}_{\mathrm{x}}\right)$ owing to the positive activity of oxygen-containing functional groups (such as $\mathrm{O}-\mathrm{H}$ groups or $\mathrm{C}-\mathrm{O}$ groups) on the wood surface, which promoted the removal of $\mathrm{NO}_{\mathrm{x}}$ by $10 \%-13 \%$. The mechanism to remove $\mathrm{NO}_{\mathrm{x}}$ in the presence of wood fibers was also deduced through FTIR spectra. When carbon black was loaded on the wood fiber, there was simultaneous removal of carbon soot and $\mathrm{NO}_{X}$. Although complete purification was not achieved, a high purification efficiency was obtained under the conditions of room temperature and no catalysts. These advantages highlight the importance of use of wood and non-thermal plasma (NTP), and this research work opens new avenues in the field of emissions treatment.
\end{abstract}

Keywords: nitrogen oxide $\left(\mathrm{NO}_{\mathrm{x}}\right)$; particulate matter $(\mathrm{PM})$; plasma discharge; wood fiber

\section{Introduction}

Diesel engines are increasingly used worldwide due to their compact size, low operating costs, and higher thermal efficiency than gasoline engines. However, their emissions consist of $\mathrm{NO}_{\mathrm{x}}, \mathrm{CO}$, $\mathrm{CO}_{2}$, hydrocarbons (HCs), formaldehyde (PAH), and particulate matter (PM). These components are harmful to human health as well as the environment [1]; hence now, there are stricter regulations upon diesel engine emissions. Various related technologies that have been developed in recent years include diesel oxidation catalysts (DOCs) [2-5], diesel particulate filters (DPFs) [6-8], catalytic-diesel particulate filters (CDPFs) [9-13], and selective catalytic reduction (SCR) [14,15], all of which add certain advantages to previous technologies. However, these new technologies still present some limitations. For instance, some studies on DOC system have revealed that the diesel fuel required to add approximately $25 \%-50 \%$ to certain amounts of precious metals (such as $\mathrm{Pt}, \mathrm{Pd}$, and cerium) to treat diesel emission more efficiently [16]. Additionally, sulfur oxidation to $\mathrm{SO}_{3}$ at high temperatures contributes to the increased deposition of metal sulfate [2]. This process of metal nanoparticles formation can seriously affect human health, as these nanoparticles may enter the human bloodstream and inhalation systems [4,5]. The SCR system has several problems such as leakage of reducing agent ammonia gas, catalyst poisoning and high costs $[14,15,17]$. DPFs have issues of difficulty in regeneration and high back pressure $[18,19]$. The CDPF is still troublesome with regards to practical applications in diesel engines, namely, the challenge of activating catalysts at low-temperatures as well as high catalyst costs due to the use of noble metals (Pt-Pd, NiAlO, $\mathrm{LaCoO}_{3}$, and $\mathrm{CoCeO}$ ) [11-13]. 
Plasma is the fourth state of matter and an ionized type of gas consisting of free electrons and ions [20]. Plasma can be divided into two groups: thermal plasma and non-thermal plasma. In thermal plasma, the electrons, ions, and neutral species have same temperature, which may exceed values of $10^{7} \mathrm{~K}$ [21]. The common application of thermal plasma is to melt hazardous materials. In the meantime, non-thermal plasma, the temperature of ions (Ti) and natural gas (Tg) are a few hundred $\mathrm{K}$ (sometimes room temperature), while the electron temperature (Te) approaches to few thousand K. This is also called non-equilibrium plasma. The nonthermal plasma (NTP) has received increasing attention in recent years as a promising technology for diesel emission conversion $[22,23]$ because it can produce excited and radical species that can induce a series of complex chemical reactions, which are difficult to obtain under normal conditions. The highlights of plasma technology include oxidation of PM at low temperature $\left(\approx 200^{\circ} \mathrm{C}\right)$, rapid response at room temperature, generation of high energized electrons within a very short interval of time to promote the desired chemical reactions to eliminate the exhaust components, no secondary pollution, and moderate capital cost [24,25]. Therefore, at present, several researchers are focused on NTP technology to purify automobile exhaust emissions. Among the most representative studies on removal of nitrogen oxides and particulate matter, there is Song C.L.'s research work [26] on approach to reduce $\mathrm{NO}_{x}, \mathrm{HC}, \mathrm{PM}$ and $\mathrm{NO}_{x}$ by deploying the dielectric barrier discharge (DBD) reactor. Therein, the effects of several parameters, such as peak voltage, frequency, and engine load on the contaminant removals was intensively investigated. The results show that the maxima of $\mathrm{PM}, \mathrm{HC}$, and $\mathrm{NO}_{x}$ removal efficiencies could reach more than $80 \%, 75 \%$, and $65 \%$, respectively. Mok et al. [27] showed that the combination of dielectric barrier discharge (DBD) and catalysis hybrid processing can be applied to remove $\mathrm{NO}_{\mathrm{x}}$ and $\mathrm{PM}$ simultaneously from diesel engine exhaust. For $\mathrm{NO}_{\mathrm{x}}$ removal, the catalysis hybrid process was able to remove about $80 \%$ of the initial $\mathrm{NO}_{\mathrm{x}}$ at the energy density of $25 \mathrm{~J} / \mathrm{L}$ and temperature of $150^{\circ} \mathrm{C}$. The removal of particulate matter did not primarily depend on the electrode structure, but was a strong function of energy density. With $80 \%$ removal efficiency, the energy yield for nitrogen oxide was $40 \mathrm{eV} / \mathrm{molecule}$ while that for particulate matter was $83 \mathrm{~kJ} / \mathrm{mg}$. Okubo M. [28] studied the simultaneous reduction of $\mathrm{PM}$ and $\mathrm{NO}_{\mathrm{x}}$ using a catalysis-combined non-thermal plasma reactor. $\gamma \mathrm{Al}_{2} \mathrm{O}_{3}$ and $\mathrm{Ag} / \gamma \mathrm{Al}_{2} \mathrm{O}_{3}$ catalysts of $2-4 \mathrm{~mm}$ diameter were used as packed pellets with carbon PM loaded among the pellets. The principle of simultaneous removal of $\mathrm{PM}$ and $\mathrm{NO}_{\mathrm{x}}$ using catalyst was discussed. $\mathrm{N}$ radicals reduced $\mathrm{NO}_{\mathrm{x}}$, while $\mathrm{PM}$ was incinerated by the oxygen radicals induced either by $\mathrm{NO}_{\mathrm{x}}$ or ozone reduction under elevated local temperatures among the pellets. The maximum $\mathrm{NO}_{\mathrm{x}}$ and $\mathrm{PM}$ removal energy efficiency were $14.2 \mathrm{~g}\left(\mathrm{NO}_{2}\right) / \mathrm{kWh}$ for $\mathrm{O}_{2}=0 \%$ and $0.92 \mathrm{~g}(\mathrm{C}) / \mathrm{kWh}$ for $\mathrm{O}_{2}=2 \%$, respectively. In comparison with the study using $\mathrm{BaTiO}_{3}$ pellets, $\mathrm{NO}_{x}$ removal energy efficiency was larger, but the PM removal was lower in the case of catalyst packed-bed reactor. M.Babaie [29] investigated the effects of non-thermal plasma on $\mathrm{NO}_{\mathrm{x}}$ emission and $\mathrm{PM}$ structure using real diesel exhaust at different discharge powers (by varying the voltage peak-peak in the range of $7.5-13.5 \mathrm{kV}$ at frequency $50 \mathrm{~Hz}$ ). The results show that plasma reactor was extremely effective for $\mathrm{NO}_{\mathrm{x}}$ emission and $\mathrm{PM}$ removal, especially for soot reduction. A maximum reduction of $73 \%$ and $37 \%$ at an energy density of $27 \mathrm{~J} / \mathrm{L}$ was found for $\mathrm{NO}_{\mathrm{x}}$ and SOF mass concentrations, respectively. With regards to PM removal efficiency, energy consumption, and PM size distribution on nucleation mode, running the DBD reactor at $12 \mathrm{kV}$ was demonstrated as the optimum operating condition for the given configuration.

In our previous studies $[7,8]$, wood fiber, a natural porous biomass material containing numerous different diameter pores, was employed, which not only adsorb PM including nano-scale particulates, but also serves a catalyst carrier with low back pressure. Compared with the inorganic materials, such as cordierite and silicon carbide that are widely used as catalyst carriers in the area of exhaust purification, the wood-fiber filter has the advantages of multi-aperture, high porosity, large specific surface, excellent adsorption capacity for PM including ultrafine particles, low cost, and ease to be employed as fuel or fertilizer after use [30]. During our previous research, Danfeng Du et al. [8] reported a new kind of diesel particulate filter using gear-shaped wood fiber filter (WFF), which met filtration efficiency of about $85 \%$, the life span of WFF was more than $90 \mathrm{~h}$. The filter had a low cost and 
simple manufacturing process and did not require extremely high quality fuel. Our previous patent [1] also indicated that the emission temperature under the condition of installing the air cooling device, the wood fiber filter showed good performances under temperature $220^{\circ} \mathrm{C}$. This exhaust temperature is typical for light-duty vehicles, or diesel vehicles run in urban and suburban [31]. The above results indicate that our research worked well for the studies that used wood fibers as materials to design diesel particulate matter filters. However, the synergistic role of plasma and wood in the processing of $\mathrm{NO}_{\mathrm{x}}$ is still unclear. As discussed above, NTP is claimed to be an appropriate system for handling low-temperature diesel exhaust gases, which is similar to the real exhaust gas temperature. Several papers have highlighted that the NTP-catalyst combination is commonly used to treat diesel exhaust gases. However, in these systems, the targets need to have low-pressure drop, thermal stability, and high mechanical strength during engine operation. Plasma generated in a wood fiber filter structure is a suitable solution for these requirements. The wood surface consists of numerous narrow holes, which avoids pressure drops and is stable with mechanical vibrations. These are some of the drawbacks of the use catalyst pellets. Herein, the aim is to evaluate the effects of wood fiber combined with NTP on the diesel exhaust treatment. The initial results of this work can open avenues for subsequent research on the manufacture of exhaust gas filter with other optimal parameters (wood material, electrode material, electrode diameter, flow rate gas, frequency, and voltage of a pulse, etc.). The target is to prove the usage of discharge dielectric barrier DBD-wood fiber combination in the field of diesel exhaust treatment.

\section{Results}

\subsection{Effect of Wood Fiber in NOx Removal}

The experiment was conducted to assess the effect of wood fibers in the exhaust filter of diesel engines by comparing the results of $\mathrm{NO}_{x}$ decrease between the case of plasma and plasma-wood fiber combination. The experimental conditions are mentioned in Section 3 (Materials and Method), the wood fiber mass was $10 \mathrm{mg}$. All these values were determined after the trial experiments. The measurement results are shown in Figure 1.

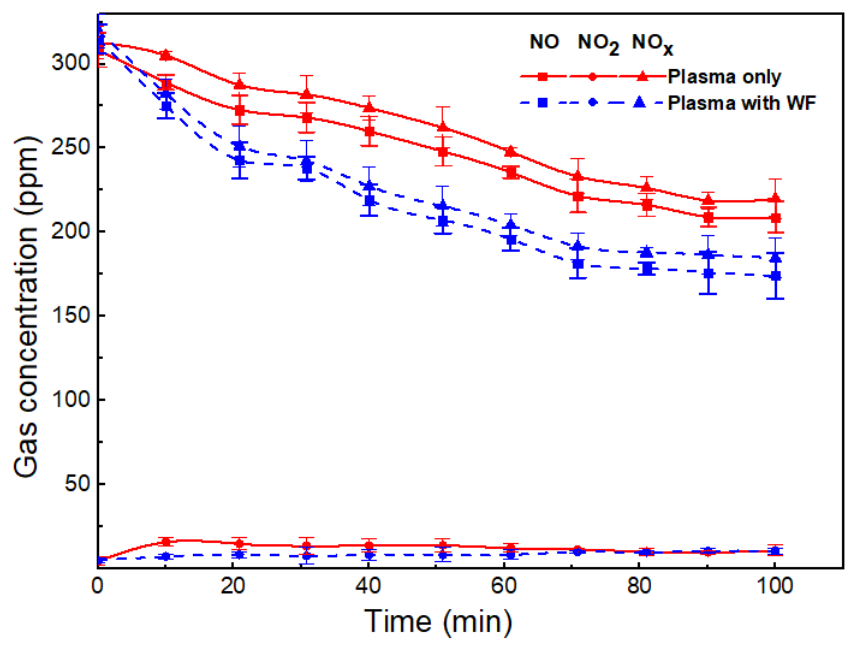

Figure 1. Gas concentrations versus elapsed time at plasma w/o wood fiber; applied voltage $7.5 \mathrm{kV}$ and SED $50 \mathrm{~J} / \mathrm{L}$ (error bars indicate the standard deviation).

The combination of plasma and wood fiber displayed significantly greater $\mathrm{NO}_{\mathrm{x}}$ reduction efficiency than the plasma alone; i.e., there was a difference of $10 \%-13 \%$ in the $\mathrm{NO}_{\mathrm{x}}$ reduction efficiency between the two methods. This phenomenon may be attributed to some changes in the chemical components of wood fibers under the action of plasma, which resulted in the increase of oxygen functional groups or free radicals on the surface of wood fibers. The main chemical components of wood include cellulose, 
hemicellulose, and lignin, which all contain numerous oxygen-containing functional groups. Under the action of plasma, the content of oxygen-containing functional group in the wood increased, which promoted the transformation of NO. Hongyan Wang et al. [32] found that after the nitrogen cold plasma treatment, $\mathrm{N}$ element was introduced onto the wood surface, and they inferred it as the $-\mathrm{NH}_{2}$ group. Moreover, the bond energy of $\mathrm{NO}$ was lower than that of $\mathrm{N}_{2}$, which made it easier for $\mathrm{N}$ in $\mathrm{NO}$ to be introduced onto the surface. These results indicate that the combination of plasma and wood has a specific nitrogen fixation effect to a certain extent.

After experiments were completed, the infrared spectrum analysis was performed for wood fibers. The absorption peak position of some functional groups are shown in Figure 2. The transmittance of wood after plasma treatment was slightly reduced, which indicates that the content of oxygen-containing functional groups changed under the action of plasma. The absorption peak of the amino group could not be clearly observed in the infrared spectrum. The reason for the phenomenon may be that the absorption peak of amino group has same wavenumber as the absorption peak of $\mathrm{O}-\mathrm{H}$, and the absorption intensity of $\mathrm{O}-\mathrm{H}$ can easily cover the absorption peak of amino group. Based on the assumption of Wang H.Y as discussed above, the enhancement of O-H peak may be partly attributed to the appearance of this amino group. As listed in the Figure 2, C-O (at $1016 \mathrm{~cm}^{-1}$ ) and $\mathrm{O}-\mathrm{H}\left(\right.$ at $3276 \mathrm{~cm}^{-1}$ ) significantly changed before and after utilizing plasma, whereas the functional groups at 1249,1690 , and $2846 \mathrm{~cm}^{-1}(\mathrm{C}=\mathrm{C}, \mathrm{C}=\mathrm{O}$, and $\mathrm{C}-\mathrm{H}$, respectively) had no significant change. The characteristic absorption peak of $\mathrm{O}-\mathrm{H}$ at $3276 \mathrm{~cm}^{-1}$ belongs to $\mathrm{O}-\mathrm{H}$ in cellulose and lignin, indicating that plasma may have affected those in the wood. The experiments also show that $\mathrm{NO}_{\mathrm{x}}$ removal increased, suggesting that the combination of wood and plasma was beneficial to promote $\mathrm{NO}_{\mathrm{x}}$ removal.

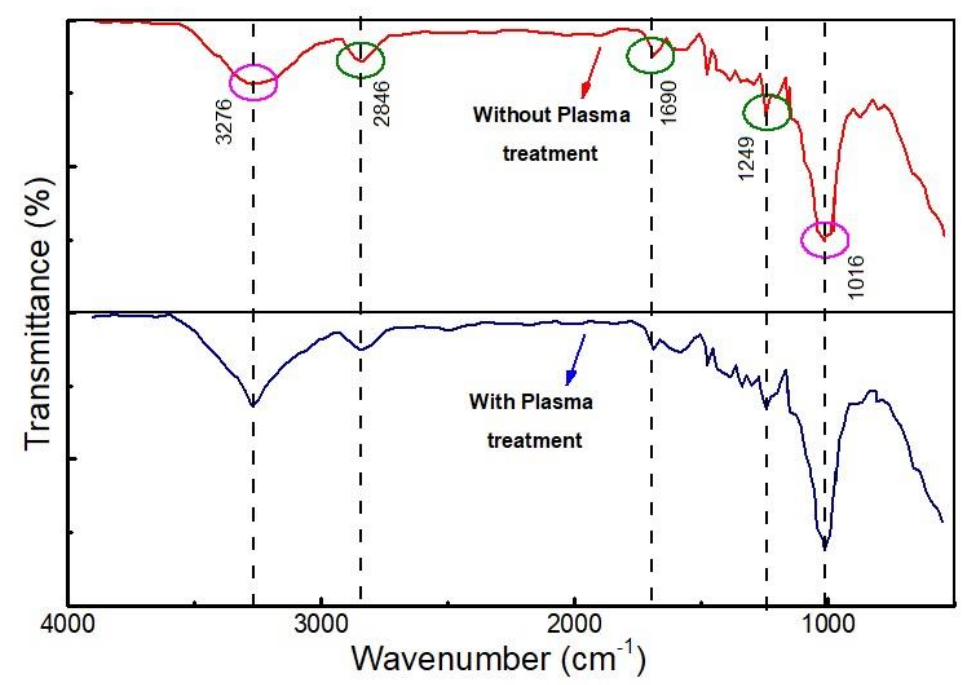

Figure 2. FTIR spectra of wood fiber w/o plasma treatment.

\subsection{Mechanism of NOx Removal in Presence of Wood Fiber}

In the pre-reactor step, under strong oxidation conditions of plasma the reactions of oxidation of $\mathrm{NO}$ to $\mathrm{NO}_{2}$ could be summarized as following by reactions (R. 1)-(R. 7):

$$
\begin{gathered}
\mathrm{O}_{2}+\mathrm{e} / \mathrm{M} \rightarrow \mathrm{e} / \mathrm{M}+\mathrm{O} \bullet+\mathrm{O} \bullet \\
\mathrm{N}_{2}+\mathrm{e} / \mathrm{M} \rightarrow \mathrm{N} \bullet+\mathrm{N} \bullet+\mathrm{e} / \mathrm{M} \\
\mathrm{O}_{2}+\mathrm{O} \bullet+\mathrm{e} / \mathrm{M} \rightarrow \mathrm{O}_{3}+\mathrm{e} / \mathrm{M} \\
\mathrm{NO}+\mathrm{N} \bullet+\mathrm{e} / \mathrm{M} \rightarrow \mathrm{N}_{2}+\mathrm{O} \bullet+\mathrm{e} / \mathrm{M} \\
\mathrm{NO}+\mathrm{O} \bullet+\mathrm{e} / \mathrm{M} \rightarrow \mathrm{NO}_{2}+\mathrm{e} / \mathrm{M}
\end{gathered}
$$




$$
\begin{aligned}
& \mathrm{NO}+\mathrm{O}_{3}+\mathrm{e} / \mathrm{M} \rightarrow \mathrm{NO}_{2}+\mathrm{O}_{2}+\mathrm{e} / \mathrm{M} \\
& \mathrm{NO}_{2}+\mathrm{N} \bullet+\mathrm{e} / \mathrm{M} \rightarrow \mathrm{N}_{2}+\mathrm{O}_{2}+\mathrm{e} / \mathrm{M}
\end{aligned}
$$

where $\mathrm{e} / \mathrm{M}$ denotes electron or excited molecules. Then, the active particle, plasma and NO entered the wood fiber reactor. Under the combined action of wood and NTP, the removal of NO was further enhanced. These results indicate that some changes took place on the surface of wood under the action of plasma conditions which changed the activation energy of wood surface and increased the oxygen-containing functional groups on the surface of the wood. As per the hypothetical argument mentioned in the previous section, oxygen-containing functional groups, such as aldehyde (R-HCO) and carboxylic acid/carboxylate (R-COOH) groups, can promote the oxidation of $\mathrm{NO}$ to $\mathrm{NO}_{2}$ as per reactions (R. 8)-(R. 10) [33,34]. Nitrogen may have been introduced as well onto the wood surface in the form of amino, which made the purification of $\mathrm{NO}_{\mathrm{x}}$ more efficient than plasma alone.

$$
\begin{gathered}
\mathrm{HCO}+\mathrm{O}_{2}+\mathrm{e} / \mathrm{M} \rightarrow \mathrm{HO}_{2}+\mathrm{CO}+\mathrm{e} / \mathrm{M} \\
\mathrm{COOH}+\mathrm{O}_{2}+\mathrm{e} / \mathrm{M} \rightarrow \mathrm{HO}_{2}+\mathrm{CO}_{2}+\mathrm{e} / \mathrm{M} \\
\mathrm{HO}_{2}+\mathrm{NO}+\mathrm{e} / \mathrm{M} \rightarrow \mathrm{OH} \bullet+\mathrm{NO}_{2}+\mathrm{e} / \mathrm{M}
\end{gathered}
$$

\subsection{Effect of Wood Fiber Loaded Carbon Soot on $\mathrm{NO}_{x}$ Removal}

The wood fiber loaded carbon black PM mass changed from 10 to $30 \mathrm{mg}$, while the initial wood mass remained $10 \mathrm{mg}$. The experimental results of the gas concentrations are shown in Figure 3 . As shown in the figure, carbon soot under plasma conditions seems to affect the removal of $\mathrm{NO}_{\mathrm{x}}$. When plasma treatment with carbon soot was loaded inside the wood fiber, after half an hour of activity the concentration of $\mathrm{NO}_{x}$ quickly reduced to $125 \mathrm{ppm}$, while $\mathrm{NO}_{\mathrm{x}}$ concentration in this case without PM decreased to $185 \mathrm{ppm}$. However, thereafter, the $\mathrm{NO}_{\mathrm{x}}$ concentration did not vary significantly after reaching approximately $115 \mathrm{ppm}$ at $1.5 \mathrm{~h}$ of observation. These results prove that presence of carbon soot in the early stage of plasma treatment contributes towards the efficiency of $\mathrm{NO}_{\mathrm{x}}$ removal. Meanwhile, the concentrations of $\mathrm{CO}$ and $\mathrm{CO}_{2}$ increased because of the incineration of PM. The collected carbon PM was effectively incinerated and can be summarized by the following reactions (R. 11)-(R. 17):

$$
\begin{gathered}
\mathrm{O}_{3}+\mathrm{SOF}+\mathrm{e} / \mathrm{M} \rightarrow \mathrm{CO}\left(\mathrm{CO}_{2}\right)+\mathrm{O}_{2}+\mathrm{H}_{2} \mathrm{O}+\mathrm{e} / \mathrm{M} \\
\mathrm{C}+\mathrm{O} \bullet+\mathrm{e} / \mathrm{M} \rightarrow \mathrm{CO}+\mathrm{e} / \mathrm{M} \\
\mathrm{C}+2 \mathrm{O} \bullet+\mathrm{e} / \mathrm{M} \rightarrow \mathrm{CO}_{2}+\mathrm{e} / \mathrm{M} \\
\mathrm{C}+\mathrm{O}_{3}+\mathrm{e} / \mathrm{M} \rightarrow \mathrm{CO}+\mathrm{O}_{2}+\mathrm{e} / \mathrm{M} \\
2 \mathrm{C}+2 \mathrm{NO}_{2}+\mathrm{e} / \mathrm{M} \rightarrow 2 \mathrm{CO}_{2}+\mathrm{N}_{2} \\
\mathrm{C}+2 \mathrm{NO}_{2}+\mathrm{e} / \mathrm{M} \rightarrow \mathrm{CO}_{2}+2 \mathrm{NO}+\mathrm{e} / \mathrm{M} \\
\mathrm{C}+\mathrm{NO}_{2}+\mathrm{e} / \mathrm{M} \rightarrow \mathrm{CO}+\mathrm{NO}+\mathrm{e} / \mathrm{M}
\end{gathered}
$$

Figure 4 showed $\mathrm{NO}_{x}$ removal with different carbon soot levels loaded inside the wood fiber. The results when carbon load was $15 \mathrm{mg}$ is already presented in Figure 3. As per Figure 4, the $\mathrm{NO}_{\mathrm{x}}$ concentration displayed same trend of decrease and reached equilibrium after about 20-30 $\mathrm{min}$ in all cases of different carbon mass loading. These results imply that carbon soot acts as a strong $\mathrm{NO}_{\mathrm{x}}$ reducing agent during the first period time active plasma; however, the removal performance deteriorates with the elapsed time. The decrease in $\mathrm{NO}_{x}$ amounts were approximately 124.5, 113.5, and $141.5 \mathrm{ppm}$ for the carbon loading of 10,15 and $30 \mathrm{mg}$, respectively after $1.5 \mathrm{~h}$ of observation. In the current experimental case with wood fiber-loaded carbon soot at $30 \mathrm{mg}$, the effect of $\mathrm{NO}_{\mathrm{x}}$ removal was 
lower than in the other two cases. This may be due to the relatively large amount of carbon filling up the holes on the wood fiber surface that spurred the formation of reactions (R. 16)-(R. 17), which led to a barrier in reducing $\mathrm{NO}$ concentration. However, the concentration of $\mathrm{CO}$ and $\mathrm{CO}_{2}$ released was higher than the cases when carbon soot was 10 and $15 \mathrm{mg}$. In fact, after the end of the observation period, the concentration of $\mathrm{CO}_{2}(30.6 \mathrm{ppm})$ was approximately double when compared with the case carbon soot load was $10 \mathrm{mg}$ (16.2 ppm). As is well-known, the PM oxidation by active particles in plasma is mainly associated with the oxidation of soluble organic matter (SOF) and carbon (soot). With further increase in PM mass, a large amount of soot (and maybe SOF too) in the reaction may promote further oxidation of PM, increasing the efficiency of purification. As presented in reaction reactions (R. 11)-(R. 17), the carbon $\mathrm{C}$ and SOF in PM can be easily oxidized to produce relatively stable chemical $\mathrm{CO}_{2}$, at the same time the chemical reactions (R. 4) and (R. 7) are promoted; thereby, the oxidation of PM and reduction of $\mathrm{NO}_{x}$ thus promoted each other. The increase in the mass of PM can enhance PM removal.

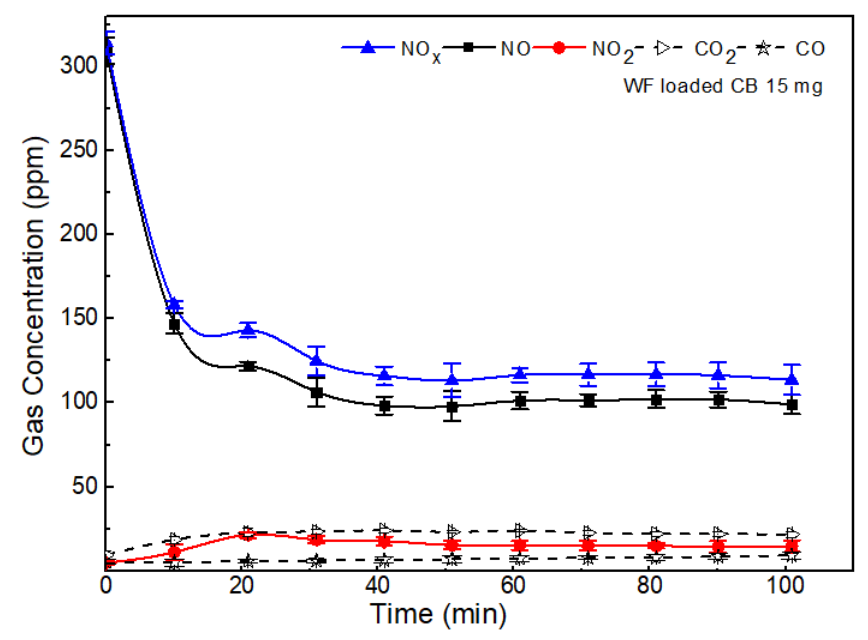

Figure 3. Effect of $\mathrm{NO}_{\mathrm{x}}$ removal in case of wood fiber loaded $\mathrm{CB}=15 \mathrm{mg}$; applied voltage $7.5 \mathrm{kV}$ and SED $50 \mathrm{~J} / \mathrm{L}$ (error bars indicate the standard deviation).

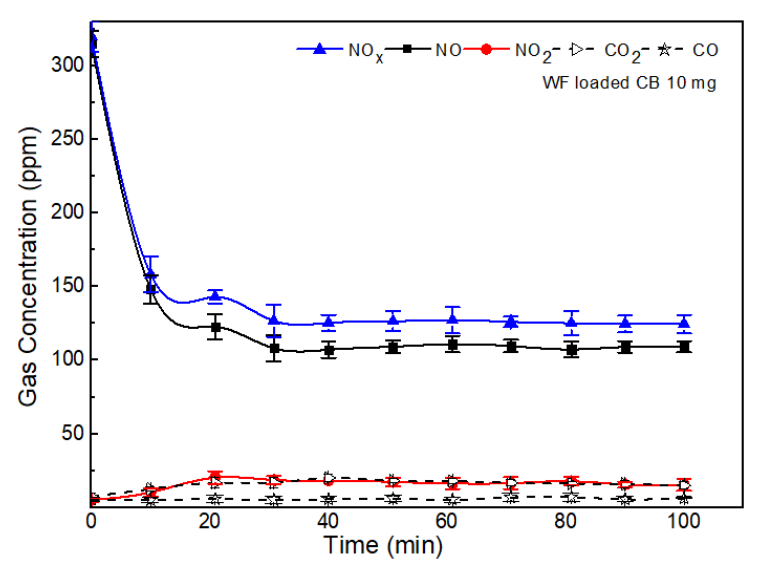

(a)

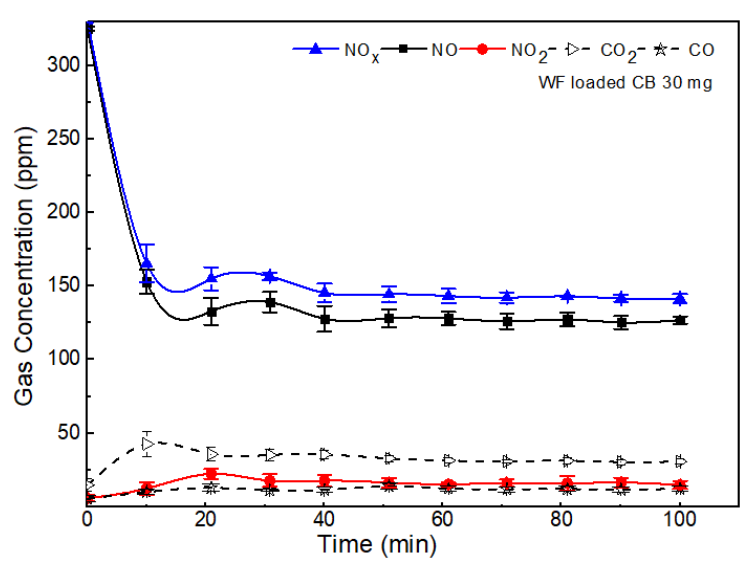

(b)

Figure 4. Effect of $\mathrm{NO}_{x}$ removal in case: (a) wood fiber loaded $\mathrm{CB}=10 \mathrm{mg}$; (b) wood fiber loaded $\mathrm{CB}=30 \mathrm{mg}$; applied voltage $7.5 \mathrm{kV}$ and SED $50 \mathrm{~J} / \mathrm{L}$ (error bars indicate the standard deviation).

Figure 5 shows the amount of PM incineration following the SED at various carbon soot mass levels. In all cases, when SED increased, the PM incineration efficiency also increased. With the increase in SED, the increase in high energy electrons in the plasma reactor led to more frequent collisions with other gas molecules, and the reaction of (R. 1)-(R. 4) intensified, resulting in more active particles and ions. Subsequently, the increase in active particles and ions, such as $\mathrm{N}, \mathrm{O}$, and $\mathrm{O}_{3}$ promoted the 
conversion of $\mathrm{NO}$ to $\mathrm{NO}_{2}$ and the reduction carbon by $\mathrm{NO}_{2}$ was also achieved, resulting in the removal of particulate matter. Nevertheless, NO could not be entirely removed due to the existence of reaction (R. 18).

$$
\mathrm{O} \bullet+\mathrm{NO}_{2}+\mathrm{e} / \mathrm{M} \rightarrow \mathrm{NO}+\mathrm{O}_{2}+\mathrm{e} / \mathrm{M}
$$

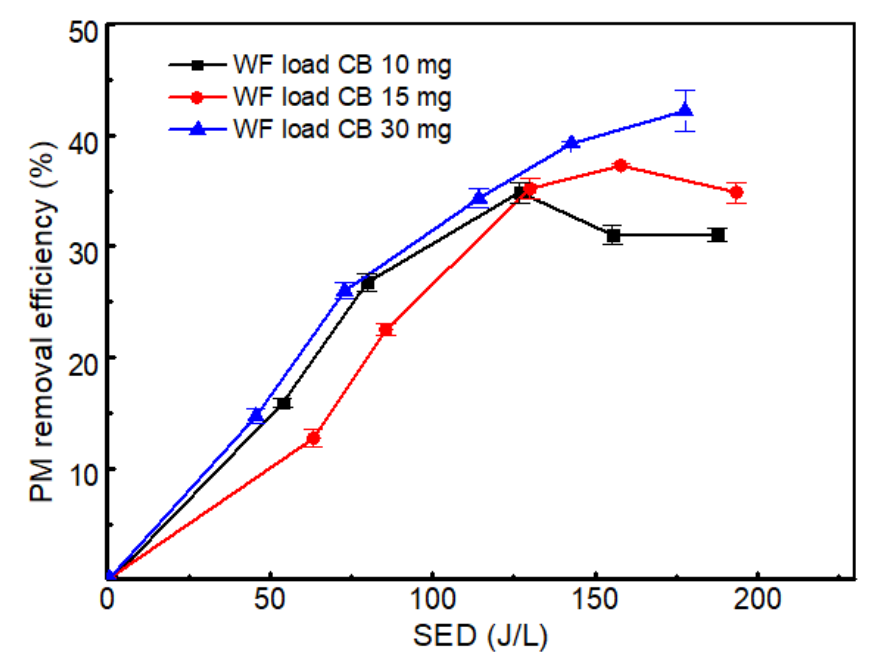

Figure 5. PM incineration at wood fiber loaded carbon black 10, 15 and $30 \mathrm{mg}$ (error bars indicate the standard deviation).

\section{Materials and Methods}

The plasma reactor structure is shown in Figure 6; the pre-reactor section is a coaxial reactor with outer material is a quartz glass tube (outer diameter $-20 \mathrm{~mm}$, inner diameter $-18 \mathrm{~mm}$, length $-250 \mathrm{~mm}$ ). The inner electrode is formed by a metal discharge wire (diameter $2 \mathrm{~mm}$ ) located at the center of the pre-reactor and main reactor. Inside the main reactor, the length of the wood fiber layer is 100 $\mathrm{mm}$, it was placed inside discharge area. The double-headed perforated Teflon (PTFE) plate provides support while the micro wood fiber was placed inside the discharge zone, as the gas passed through the perforated hole and wood fiber. An aluminum mesh ( $350 \mathrm{~mm}$ length) was wrapped over the outer quartz glass tube, which was the grounded electrode. Notably, no gap should be present between the mesh and dielectric in order to prevent the power loss.

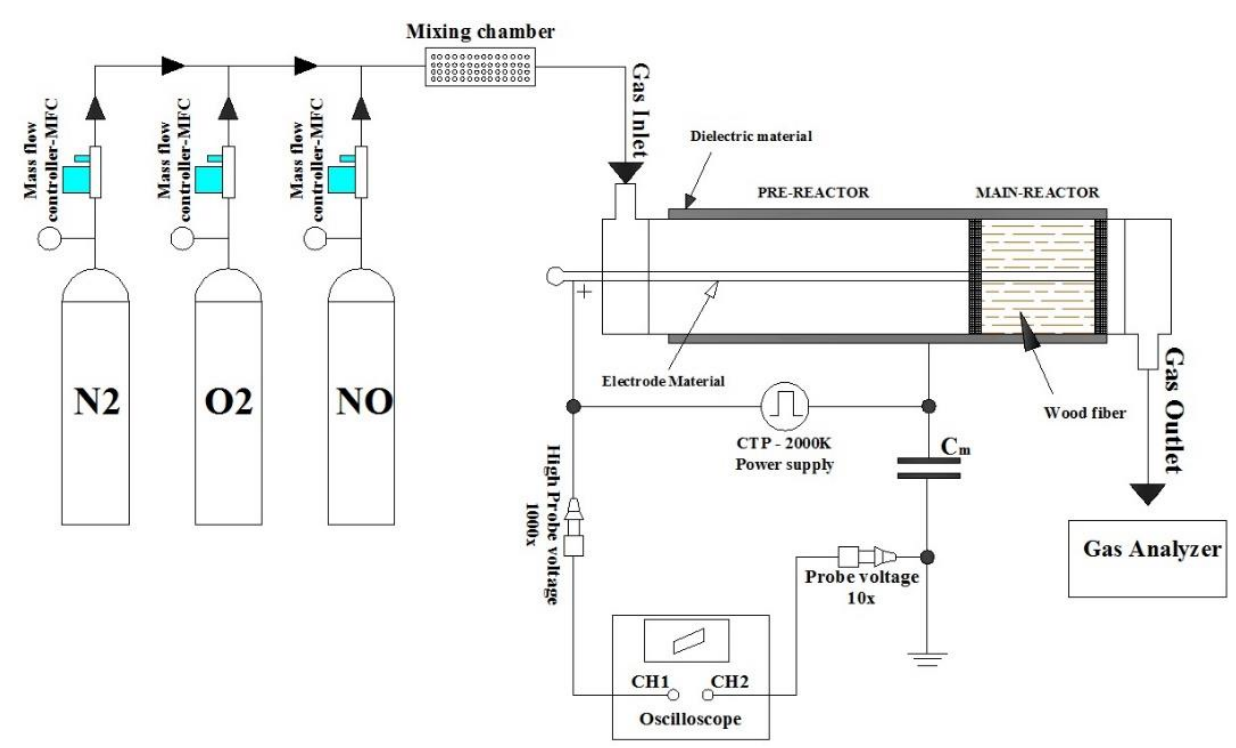

Figure 6. Schematic of experimental setup. 
The wood fibers were processed into micro wood fibers to improve the physical and chemical properties of wood fibers. The processing technology is as follows. The wood was treated into cubes of $60 \times 60 \times 2000 \mathrm{~mm}$ which were cut along the grain by a chipping machine, and the micron-thickness shavings are shown in Figure 7a. Afterwards, the shavings were processed into the micro wood fibers of length 30 to $50 \mathrm{~mm}$, width 1 to $2 \mathrm{~mm}$, and average thickness of about $55 \mu \mathrm{m}$ via a kneading machine. Finally, micro wood fiber was heat-treated in $160^{\circ} \mathrm{C}$ environment using muffle furnace (WD1100, Shanghai, China), and Figure $7 \mathrm{~b}$ is the result after processing pine wood.

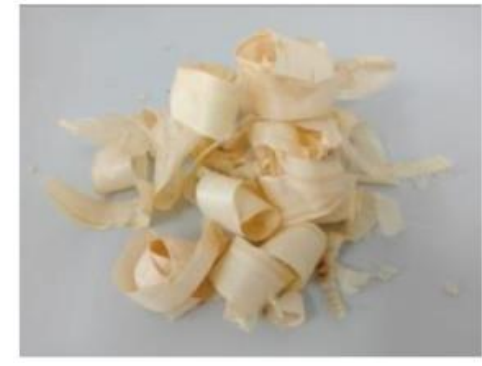

(a)

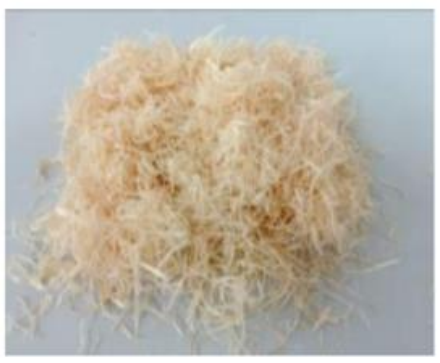

(b)

Figure 7. Wood fiber: (a) after being cut along; (b) micro wood fiber following heat treatment.

The purpose of this experiment is closer to the actual diesel exhaust filter, the carbon soot PM sampled from carbon black (CB) was attached to wood fibers via impregnation method (Figure 8). Carbon black was stirred in distilled water solution using digital mixer (JJ-1A, Jiangsu, China) for $1 \mathrm{~h}$. The wood fibers were soaked in carbon black-water solution for $2 \mathrm{~h}$. Thereafter, the wood fibers were placed in a constant temperature drying oven (FT202 2-A, Zhejiang, China) at $80^{\circ} \mathrm{C}$ for $1 \mathrm{~h}$. The wood fibers were continued to be baked in the kiln (WD100, Shanghai, China) at $100{ }^{\circ} \mathrm{C}$ for one hour. Finally, the amount of carbon PM that was impregnated into the wood fibers was weighed using an electronic scale. The experiment was performed several times to determine the amount of carbon PM loaded into the wood fiber to suit the experimental purposes mentioned in the following section. Depending on the purpose of the experiments, the wood fiber had two functions, including participate in the process convert NO concentration progress and carbon soot absorbed.

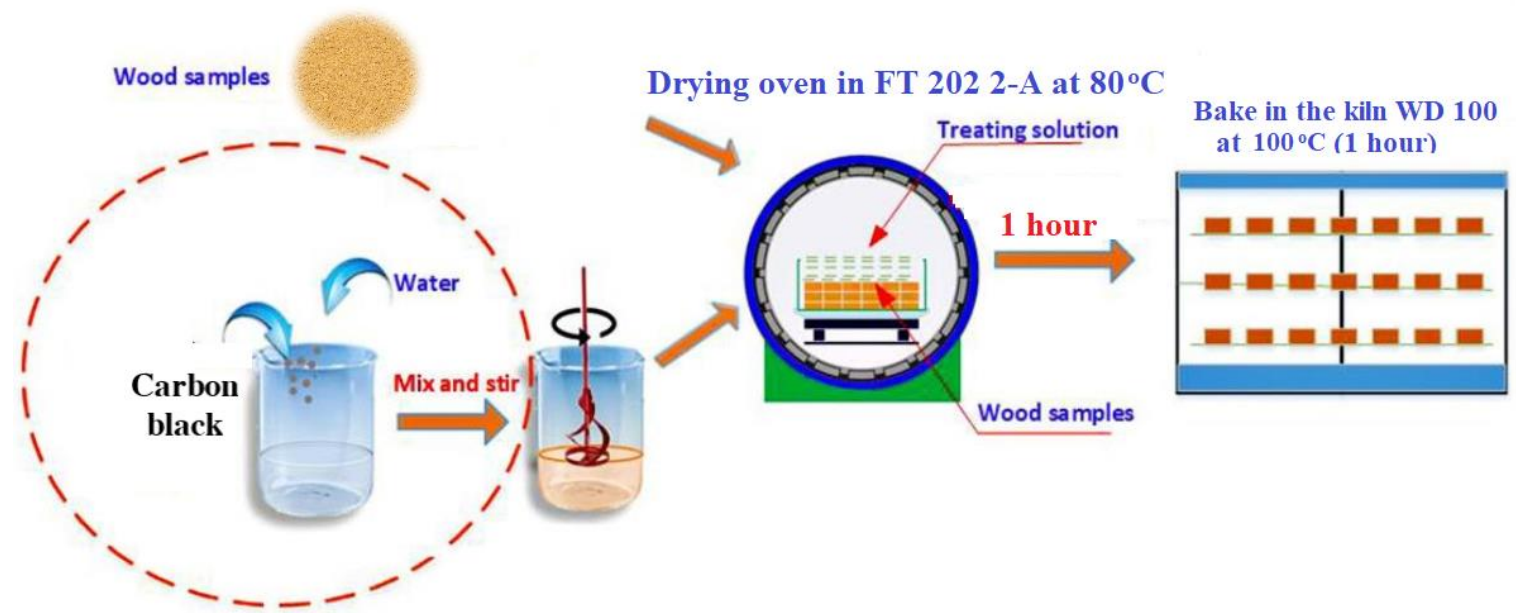

Figure 8. Treatment process of wood fibers with carbon black aqueous solution.

The simulated gas had a NO concentration of $300 \mathrm{ppm}, \mathrm{O}_{2}$ at $2 \%$, and $\mathrm{N}_{2}$ as remaining gas. The gas flow was controlled at $\mathrm{Q}=2 \mathrm{~L} / \mathrm{min}$ by mass flow controller MFC and was run through mixing chamber. The outlet gas concentrations of $\mathrm{NO}, \mathrm{CO}$, and $\mathrm{CO}_{2}$ were measured using a gas analyzer (NHA-506, GuangDong, China). For each experiment, the data of gas concentration were collected three times, 
then use the standard deviation (STDEV) function in Microsoft Excel to perform error bars value calculations. A CTP-2000K intelligent electron impactor (Suman Electronics Co., Nanjing, China) was employed for the DBD reactor which could adjust pulse peak-to-peak voltage $0-30 \mathrm{kV}$ and frequency of $0-20 \mathrm{kHz}$. The digital oscilloscope was used to determine discharge parameter power discharge $\mathrm{P}$ via Lissajous method. The applied voltage was measured using a $60-\mathrm{MHz}$ digital oscilloscope (Rigol DS1062CA, Beijing, China). This system was equipped with a passive high-voltage probe (P6015A, Tektronix, Beaverton, OR, USA) and voltage probe (P6020, Tektronix, Beaverton, OR, USA) to measure high voltage and extend the voltage on micar monitor capacitor $C_{m}$ of $0.47 \mu f$, respectively. Notably, the monitor capacitor capacitance value $C_{m}$ is chosen to be large compared to the capacitance of the actuator without plasma discharge (sometimes called "cold" capacitance). The instantaneous power dissipated by the actuator is:

$$
P(W)=V_{a}(t) \cdot I_{a}(t)=V_{a}(t) \cdot C_{m} \frac{d V_{m}(t)}{d t}
$$

The discharge power over a period $\mathrm{T}$ is obtained using Equation (1) and change of variables:

$$
\mathrm{P}=\frac{1}{\mathrm{~T}} \int_{0}^{\mathrm{T}} \mathrm{V}_{\mathrm{a}}(\mathrm{t}) \cdot \mathrm{C}_{\mathrm{m}} \frac{\mathrm{dV} \mathrm{m}(\mathrm{t})}{\mathrm{dt}} \mathrm{dt}=\frac{1}{\mathrm{~T}} \int \mathrm{V}_{\mathrm{a}} \cdot \mathrm{C}_{\mathrm{m}} \mathrm{dV} \mathrm{V}=\frac{1}{\mathrm{~T}} \oint_{\substack{\text { one } \\ \text { cycle }}} \mathrm{V}_{\mathrm{a}} \mathrm{dQ}_{\mathrm{m}}
$$

where $\mathrm{V}_{\mathrm{a}}$ is the voltage across the reactor and $\mathrm{Q}_{\mathrm{m}}$ is the charge on the monitor capacitor. The instantaneous capacitor charge $Q_{m}$ and the actuator voltage $V_{a}$ plotted against each other generate a Lissajous curve in the $V_{a}-Q_{m}$ curve. Figure 9 show that the area inside closed Lissajous curve divided by the cycle period $\mathrm{T}$ is equal to the actuator power.

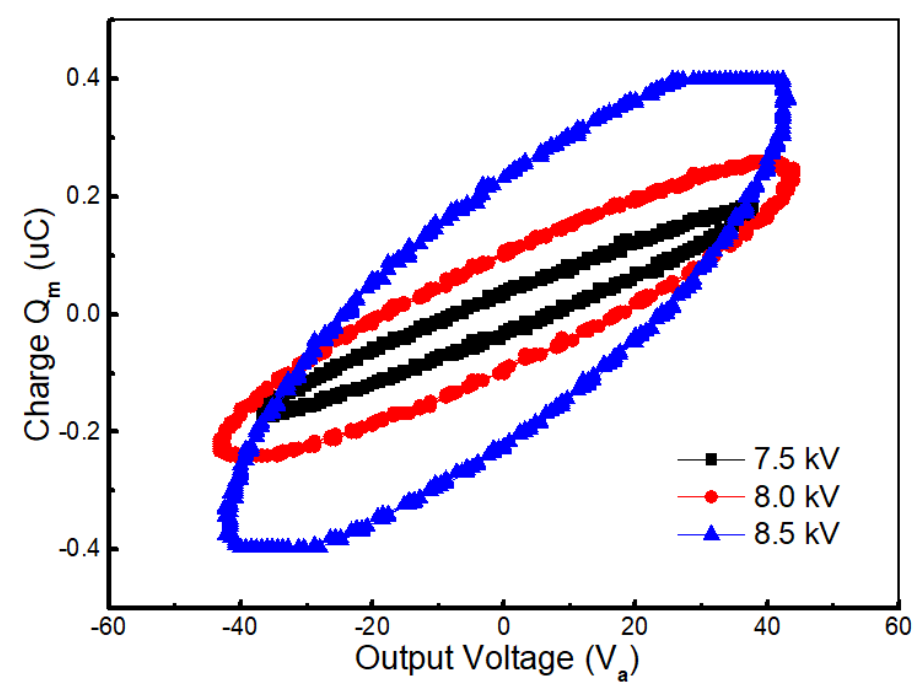

Figure 9. Waveforms of V-Q Lissajous at applied voltage $\mathrm{V}=7.5 \mathrm{kV}, 8.0 \mathrm{kV}$ and $8.5 \mathrm{kV}$.

The specific energy density (SED) value was calculated by dividing the discharge power $\mathrm{P}(\mathrm{W})$ obtained from V-Q Lissajous by the gas flow $\mathrm{Q}(\mathrm{L} / \mathrm{min})$ :

$$
\operatorname{SED}(\mathrm{J} / \mathrm{L})=\frac{60 \mathrm{P}}{\mathrm{Q}}
$$


The PM removal efficiency $\eta(\%)$ was obtained from the mass of carbon soot before $\left(C_{1}\right.$ in $\left.\mathrm{mg}\right)$ and after plasma treatment $\left(C_{2}\right.$ in $\left.\mathrm{mg}\right)$.

$$
\eta(\%)=\frac{C_{1}-C_{2}}{C_{1}} \times 100 \%
$$

Figure 9 shows an illustration of V-Q Lissajous waveforms for the DBD reactor from the display of a digital oscilloscope at an applied voltage from $7.5 \mathrm{kV}$ (SED $50 \mathrm{~J} / \mathrm{L}$ ) to $8.5 \mathrm{kV}$ (SED 186.5 J/L). These values were maintained constant throughout the experiments. For better understanding the role of wood fiber on $\mathrm{NO}_{\mathrm{x}}$ removal, the wood fibers (blank samples) that did not participate in the experiment and the wood fibers after plasma treatment were scanned at $4 \mathrm{~cm}^{-1}$ resolution from $4000 \mathrm{~cm}^{-1}$ to $400 \mathrm{~cm}^{-1}$ via a Fourier transform infrared spectrometer (FTIR) (Frontier, Perkin Elmer Co., Ltd., Waltham, MA, USA). This method was used to obtain the infrared spectrum of the absorption peaks of different functional groups' positions of the wood fiber.

\section{Conclusions}

The effects of wood fiber combined with non-thermal plasma on decrease in $\mathrm{NO}_{\mathrm{x}}$ and $\mathrm{PM}$ were investigated.

1. Compared with NTP, the addition of wood fiber could improve the conversion effect of $\mathrm{NO}_{\mathrm{x}}$ by about $10 \%-13 \%$, via the change in wood fiber properties. Following NTP treatment of wood fiber, oxygen-containing functional groups (such as $\mathrm{O}-\mathrm{H}$ groups or $\mathrm{C}-\mathrm{O}$ groups) on the wood surface provided positive activity and amino groups were introduced on the wood surface, which promoted the removal of $\mathrm{NO}_{\mathrm{x}}$.

2. The FTIR analysis showed that the chemical components of wood fiber was changed after plasma treatment. Hence, an initial mechanism for the removal of $\mathrm{NO}_{\mathrm{x}}$ in the presence of wood fibers has also been introduced.

3. The carbon soot loaded on wood fiber played the role of a reducing agent, promoting the simultaneous removal of carbon soot and $\mathrm{NO}_{\mathrm{X}}$. The results show that in the initial stages of turning on the plasma (about 20-30 min), carbon had a stronger effect and led to best $\mathrm{NO}_{\mathrm{x}}$ removal efficiency. Thereafter, $\mathrm{NO}_{\mathrm{x}}$ concentration fell into a saturation state. These results imply that as carbon became older, its role in supporting the removal of $\mathrm{NO}_{\mathrm{x}}$ was no longer evident. When the mass of carbon was increased, the concentration of $\mathrm{CO}$ and $\mathrm{CO}_{2}$ released was higher. Therefore, to treat $\mathrm{NO}_{\mathrm{x}}$ in the presence of PM, PM is required to be continuously regenerated during plasma operation. These results are suitable for future practical applications on real diesel engines because DPM components are constantly refreshed during engine operation. Higher the amount of fresh $\mathrm{PM}$, higher is the $\mathrm{NO}_{\mathrm{x}}$ removal efficiency at this time.

4. The increase in specific energy density had a good effect on the removal of carbon soot in a certain region. With combination of plasma and wood fiber, the complete elimination of $\mathrm{NO}_{\mathrm{x}}$ and PM is not yet achieved. This study provides a new method in the field of emissions treatment and the presented results are a premise to adjust the structure of plasma device with incorporation of wood fibers. The design of the plasma-wood fiber reactor needs to be completed, not only from the electrical engineering standpoint, but also using the multidisciplinary approach in the relevant fields of mechanical, chemical, and physical design parameters with the target to increase residence time for $\mathrm{PM}$ decomposition and reduction of $\mathrm{NO}_{\mathrm{x}}$ rate inside the reactor with highest air purification effect.

\section{Patents}

Guo XR, Liu YX, Du DF, An air cooling device for PM filter made of long wood fiber used in diesel engine exhaust purification, ZL 20141 0095027.3, 2014 (In Chinese).

Author Contributions: X.G. and K.H.H., data curation; X.G., K.H.H. and D.D., formal analysis; D.D., resources; K.H.H. writing - original draft; X.G. and D.D., writing-review and editing; X.G., funding acquisition and supervision. All authors have read and agreed to the published version of the manuscript. 
Funding: This research was funded by the National Natural Science Foundation of China, grant number 51972050 and the Fundamental Research Funds for the Central Universities, grant number 2572017EB04.

Acknowledgments: The authors gratefully acknowledge the academic support of the Lab of Automobile Emission Testing and Control Laboratory, College of Mechanical and Electric Engineering at Northeast Forestry University, Harbin, China; the Department of Chemical and Biological Engineering, Jeju National University, Korea and the Department of Science and Technology, Quang Ninh, Viet Nam. Also, the authors would like to thanks the reviewer for their valuable remarks and comments.

Conflicts of Interest: The authors declare no conflict of interest.

\section{References}

1. Jiaqiang, E.; Pham, M.; Zhao, D.; Deng, Y.; Le, D.; Zuo, W.; Zhu, H.; Liu, T.; Peng, Q.; Zhang, Z. Effect of different technologies on combustion and emissions of the diesel engine fueled with biodiesel: A review. Renew. Sustain. Energy Rev. 2017, 80, 620-647.

2. Prasad, R.; Bella, V.R. A review on diesel soot emission, its effect and control. Bull. Chem. React. Eng. Catal. 2010, 5, 69. [CrossRef]

3. Wade, J.; Farrauto, R. Controlling emissions of pollutants in urban areas. In Metropolitan Sustainability; Elsevier: Amsterdam, The Netherlands, 2012; pp. 260-291.

4. Jung, H.; Kittelson, D.B.; Zachariah, M.R. The influence of a cerium additive on ultrafine diesel particle emissions and kinetics of oxidation. Combust. Flame 2005, 142, 276-288. [CrossRef]

5. Brewer, G.J. Risks of copper and iron toxicity during aging in humans. Chem. Res. Toxicol. 2010, 23, 319-326. [CrossRef]

6. Khair, M.K. A Review of Diesel Particulate Filter Technologies; 0148-7191; SAE Technical Paper; SAE: Warrendale, PA, USA, 2003.

7. Guo, X.; Du, D.; Wang, F.; Ma, Y.; Yang, C.; Zhang, H.-Z. Study on test instrument and filtration theory of the carbonized micron wood fiber DPF. Microporous Mesoporous Mater. 2011, 142, 655-660. [CrossRef]

8. Du, D.; Guo, X.; Xu, Y.; Yang, X. Performance study about a new kind wood fiber filter element utilized in capturing diesel particulate material. J. Wood Sci. 2019, 65, 12. [CrossRef]

9. Wang, Z.; Jiang, Z.; Shangguan, W. Simultaneous catalytic removal of NOx and soot particulate over Co-Al mixed oxide catalysts derived from hydrotalcites. Catal. Commun. 2007, 8, 1659-1664. [CrossRef]

10. Wang, Z.; Shangguan, W.; Su, J.; Jiang, Z. Catalytic oxidation of diesel soot on mixed oxides derived from hydrotalcites. Catal. Lett. 2006, 112, 149-154. [CrossRef]

11. Makshina, E.; Sirotin, S.; Yushchenko, V.; Mazo, G.; van den Berg, M.; Klements'ev, K.; Grünert, W.; Romanovskii, B. Nanocomposites based on $\mathrm{LaCoO} 3$ and mesoporous molecular sieves: Preparation and physicochemical and catalytic properties. Kinet. Catal. 2006, 47, 49-53. [CrossRef]

12. Zou, G.; Chen, M.; Shangguan, W. Promotion effects of $\mathrm{LaCoO} 3$ formation on the catalytic performance of Co-La oxides for soot combustion in air. Catal. Commun. 2014, 51, 68-71. [CrossRef]

13. Kirienko, P.; Solov'ev, S.; Orlik, S. Effect of $\mathrm{CeO} 2$ on the properties of the Pd/Co $3 \mathrm{O}$ 4/cordierite catalyst in the conversion of CO, NO, and hydrocarbons. Theor. Exp. Chem. 2010,46,39-44. [CrossRef]

14. Apostolescu, N.; Geiger, B.; Hizbullah, K.; Jan, M.; Kureti, S.; Reichert, D.; Schott, F.; Weisweiler, W. Selective catalytic reduction of nitrogen oxides by ammonia on iron oxide catalysts. Appl. Catal. B Environ. 2006, 62, 104-114. [CrossRef]

15. Yoshida, K.; Okubo, M.; Yamamoto, T. Distinction between nonthermal plasma and thermal desorptions for NOx and $\mathrm{CO}_{2}$. Appl. Phys. Lett. 2007, 90, 131501. [CrossRef]

16. Shangguan, W.; Zou, G.; Jiang, Z. Simultaneous Catalytic Removal of Diesel Soot and NOx; Springer: Berlin/Heidelberg, Germany, 2019.

17. Miessner, H.; Francke, K.-P.; Rudolph, R.; Hammer, T. NOx removal in excess oxygen by plasma-enhanced selective catalytic reduction. Catal. Today 2002, 75, 325-330. [CrossRef]

18. Sato, S.; Kimura, M.; Aki, T.; Koyamotor, I.; Takashima, K.; Katsura, S.; Mizuno, A. A removal system of diesel particulate using electrostatic precipitator with discharge plasma. In Proceedings of the Fourtieth IAS Annual Meeting. Conference Record of the 2005 Industry Applications Conference, Kowloon, HK, China, 2-6 October 2005; pp. 2203-2206.

19. Yezerets, A.; Currier, N.W.; Eadler, H.A.; Suresh, A.; Madden, P.F.; Branigin, M.A. Investigation of the oxidation behavior of diesel particulate matter. Catal. Today 2003, 88, 17-25. [CrossRef] 
20. Gomez, E.; Rani, D.A.; Cheeseman, C.; Deegan, D.; Wise, M.; Boccaccini, A. Thermal plasma technology for the treatment of wastes: A critical review. J. Hazard. Mater. 2009, 161, 614-626. [CrossRef]

21. Lu, W.; Abbas, Y.; Mustafa, M.F.; Pan, C.; Wang, H. A review on application of dielectric barrier discharge plasma technology on the abatement of volatile organic compounds. Front. Environ. Sci. Eng. 2019, 13, 30. [CrossRef]

22. Zhang, X.; Feng, W.; Yu, Z.; Li, S.; Zhu, J.; Yan, K. Comparison of styrene removal in air by positive and negative DC corona discharges. Int. J. Environ. Sci. Technol. 2013, 10, 1377-1382. [CrossRef]

23. Zhang, H.; Li, K.; Li, L.; Liu, L.; Meng, X.; Sun, T.; Jia, J.; Fan, M. High efficient styrene mineralization through novel NiO-TiO2-Al2O3 packed pre-treatment/treatment/post-treatment dielectric barrier discharge plasma. Chem. Eng. J. 2018, 343, 759-769. [CrossRef]

24. Raju, B.R.; Reddy, E.L.; Karuppiah, J.; Reddy, P.M.K.; Subrahmanyam, C. Catalytic non-thermal plasma reactor for the decomposition of a mixture of volatile organic compounds. J. Chem. Sci. 2013, 125, 673-678. [CrossRef]

25. Ondarts, M.; Hajji, W.; Outin, J.; Bejat, T.; Gonze, E. Non-Thermal Plasma for indoor air treatment: Toluene degradation in a corona discharge at ppbv levels. Chem. Eng. Res. Des. 2017, 118, 194-205. [CrossRef]

26. Chong-Lin, S.; Feng, B.; Ze-Min, T.; Fang-Cheng, L.; Qi-Fei, H. Simultaneous removals of NOx, HC and PM from diesel exhaust emissions by dielectric barrier discharges. J. Hazard. Mater. 2009, 166, 523-530.

27. Mok, Y.S.; Huh, Y.J. Simultaneous Removal of Nitrogen Oxides and Particulate Matters from Diesel Engine Exhaust using Dielectric Barrier Discharge and Catalysis Hybrid System. Plasma Chem. Plasma Process. 2005, 25, 625-639. [CrossRef]

28. Okubo, M.; Yamada, H.; Yoshida, K.; Kuroki, T. Simultaneous Reduction of Diesel Particulate and NOx Using a Catalysis-Combined Nonthermal Plasma Reactor. IEEE Trans. Ind. Appl. 2010, 53, 5875-5882. [CrossRef]

29. Babaie, M.; Kishi, T.; Arai, M.; Zama, Y.; Furuhata, T.; Ristovski, Z.; Rahimzadeh, H.; Brown, R. Influence of non-thermal plasma after-treatment technology on diesel engine particulate matter composition and NOx concentration. Int. J. Environ. Sci. Technol. 2016, 13, 221-230. [CrossRef]

30. Guo, X.; Du, D.; Qi, Z.; Peng, W.; Song, H. Microstructure characterization of wood fiber PIT adsorbingultrafine particles emitted by diesel engine and simulation of its influence factors. Wood Res. 2016, 61, 175-186.

31. Yao, S. Plasma reactors for diesel particulate matter removal. Recent Pat. Chem. Eng. 2009, 2, 67-75. [CrossRef]

32. Wang, H.Y.; Du, G.B.; Li, Q.; Xu, R.Y.; Yuan, S.F. Bonding Performance of Wood Treatment by Oxygen and Nitrogen Cold Plasma. Appl. Mech. Mater. 2014, 633-634, 583-588. [CrossRef]

33. Nie, Y.; Wang, J.; Zhong, K.; Wang, L.; Guan, Z. Synergy study for plasma-facilitated C2H4 selective catalytic reduction of NOX over ag $/ \gamma-\mathrm{Al} 2 \mathrm{O} 3$ catalyst. IEEE Trans. Plasma Sci. 2007, 35, 663-669. [CrossRef]

34. Nolte, J.; Grussdorf, J.; Temps, F.; Wagner, H.G. Kinetics of the reaction HOCO+ O2 in the gas phase. Z. Für Nat. A 1993, 48, 1234-1238. [CrossRef]

(C) 2020 by the authors. Licensee MDPI, Basel, Switzerland. This article is an open access article distributed under the terms and conditions of the Creative Commons Attribution (CC BY) license (http://creativecommons.org/licenses/by/4.0/). 